\title{
Overgrowth-macrocephaly-facial dysmorphism syndrome
}

INSERM

\section{Source}

INSERM. (1999). Orphanet: an online rare disease and orphan drug data base.

Overgrowth-macrocephaly-facial dysmorphism syndrome. ORPHA:137634

This syndrome is characterised by tall stature, learning difficulties and facial dysmorphism. 